\title{
La biopsia renal: importancia clínica
}

\author{
Conferencia de ingreso a Sociedad Médica de Valdivia \\ Dr. J. Daniel Carpio Paniagua
}

\section{INTRODUCCIÓN}

La biopsia renal es un procedimiento médico complejo, conocido desde mediados del siglo XX, cuando los daneses Iversen y Brun publican en 1951 su primera experiencia luego de adaptar la técnica de biopsia hepática para la obtención de tejido renal'.

Respecto de la técnica, Furness reflexiona hace unos años: "tomar una biopsia no es un procedimiento trivial", lo cual tiene relación con el momento crucial en que se realiza el procedimiento, la imprescindible experiencia del ejecutor y las posibles complicaciones derivadas del mismo. Por otra parte habla de "que el tejido obtenido es invariablemente más pequeño de lo que el patólogo desearía"2, lo cual es en la mayoría de los casos el primer pensamiento que se presenta en la mente del nefropatólogo al ver los cordones tisulares de escasa longitud y más aún de mínimo grosor.

El desarrollo de la Nefropatología en los últimos 20 años ha sido vertiginoso, especialmente en lo referente a los trastornos glomerulares. En este período se consolidó la expresión de glomerulopatías para incluir las enfermedades con signos morfológicos inflamatorios llamadas glomerulonefritis, y aquellas que carecen de esos rasgos. EI progreso ha sido multifacético y las ciencias básicas aplicadas al estudio del riñón y la nefrología experimental fueron pilares de su desarrollo. ${ }^{3}$

\section{INDICACIONES DE BIOPSIA RENAL E IMPORTANCIA CLÍNICA}

Son tres grupos de pacientes los que se benefician mayormente con este procedimiento: a. pacientes con síndrome nefrótico, b. aquellos con compromiso renal en el contexto de una enfermedad sistémica y c. los pacientes con falla renal aguda. Es claro que, una vez obtenido el diagnóstico anátomo-patológico se procederá a realizar las intervenciones terapéuticas necesarias, evaluando simultáneamente el pronóstico de acuerdo al tipo de enfermedad renal que afecte al paciente.

En otro grupo de pacientes la biopsia renal puede aportar importante información respecto del diagnóstico, entre los que se cuentan aquellos que se manifiestan clínicamente como proteinuria no-nefrótica, hematuria y falla renal crónica.

Por último, en el grupo de pacientes receptores de un trasplante renal, el rol de la biopsia es fundamental en la toma de decisiones respecto de la agresividad del tratamiento, ajuste de dosis de medicamentos y otras medidas eventuales complementarias ${ }^{4}$.

Por otra parte, la biopsia renal es la única forma de describir nuevas enfermedades, incluyendo el efecto adverso de diversas drogas.

Finalmente, es absolutamente requerida en estudios clínicos para asegurar que la severidad de una enfermedad determinada es comparable entre los diferentes grupos de estudio, además de servir como base para la evaluación de efectos terapéuticos ${ }^{5}$.

\section{OBTENCIÓN DE LA MUESTRA}

El procedimiento de obtención de tejido renal a través de una biopsia debe ser realizado por un nefrólogo, radiólogo o urólogo, dependiendo de la experiencia del centro y el método elegido, bajo condiciones de estricta asepsia, ya sea por punción renal con aguja o con pistola neumática, idealmente bajo visión ecográfica, o bien por visión directa del riñón, por 
método laparoscópico o por cirugía abierta, tomando una cuña tisular. En el primer caso el riesgo es no obtener parénquima renal o tejido sin glomérulos, que es habitualmente el blanco de gran parte de las patologías renales. Por el contrario, en las biopsias bajo visión directa, se asegura la obtención de buena cantidad de corteza, con una incidencia de complicaciones muy baja, dada la posibilidad de realizar una buena hemostasia. Es ideal confirmar la existencia de corteza renal observando el tejido obtenido con una lupa a contra-luz o bajo un microscopio de disección ${ }^{2,4}$.

\section{PROCESAMIENTO DE LA MUESTRA}

En este punto es importante definir la cantidad de tejido adecuado y cuánto enviar para cada técnica a realizar. Esto dependerá del objetivo planteado previo a la biopsia. En los casos de punción de riñón nativo, el ideal es siempre dividir la muestra en tres fragmentos, el menor para microscopía electrónica, que se fija en glutaraldehído al 2,5\%; otro pequeño trozo para inmunofluorescencia, enviado en fresco o mejor aún en solución de Michel y la mayor fracción para microscopía de luz, en formaldehído al 10\% tamponado. En los casos de biopsia de riñón trasplantado se debe asegurar una cantidad de tejido suficiente para examinar con microscopía de luz.

Los cortes histológicos de microscopía óptica deben ser múltiples y observados con tinción corriente de hematoxilina-eosina y otras tinciones histoquímicas especiales, para evaluar los diversos componentes del parénquima renal, como por ejemplo tinción de PAS (ácido periódico de Schiff), tricrómico de Masson, metenamina de plata de Jones y otras más específicas como Rojo Congo (determinación de amiloide). Para pesquisar lesiones que pueden ser focales (que comprometen sólo algunas áreas de la corteza renal) o segmentarias (sólo parte de un glomérulo) necesariamente deben examinarse cortes seriados de la muestra.

Se evalúa obligatoriamente en cada espécimen los glomérulos, túbulos renales, vasos sanguíneos y el intersticio renal.

En lo relativo a la microscopía de inmunofluorescencia, ésta trata de identificar una reacción antígeno-anticuerpo, incorporando anticuerpos contra inmunoglobulinas, fracciones del complemento, fibrinógeno y cadenas livianas de las inmunoglobulinas, al tejido previamente congelado y que se secciona con crióstato. La reacción es revelada por medio de una sustancia que emite una señal luminosa observada en un microscopio especial, en forma granular o lineal, ya sea en el mesangio y/o en los capilares glomerulares, cuyas imágenes representativas son captadas por medio de cámara digital y almacenadas en una microteca computacional.

Finalmente la ultraestructura del riñón es examinada con microscopio de transmisión, obteniendo imágenes fotográficas. Los objetivos de ésta son la confirmación de los hallazgos de la inmunofluorescencia, vale decir determinar la localización de depósitos electro-densos del tipo complejos inmunes, estructuras virales o del tipo interferón (estructuras tubulo-reticulares) y alteraciones de la membrana basal, entre otros $2,4,5$

\section{EVALUACIÓN DIAGNÓSTICA}

El diagnóstico anátomo-patológico final de una biopsia renal es actualmente el resultado del análisis de la metodología triple utilizada en la mayoría de los centros especializados: 1.- los hallazgos de la microscopía óptica o de luz, 2.el resultado de la microscopía de inmunofluorescencia y 3.- los hallazgos ultraestructurales de la microscopía electrónica, sumado todo esto al análisis en conjunto con los antecedentes clínicos, idealmente aportados en reuniones de diagnóstico entre los clínicos y el patólogo.

Los objetivos principales de la biopsia renal son establecer un diagnóstico (o al menos excluir otras posibilidades diagnósticas de similar presentación clínica), indicar la severidad o actividad de la lesión ("grado") y por último, establecer la cuantía del daño irreversible ("estado") ${ }^{2}$.

Existe un porcentaje de alrededor del 10\% de las biopsias en que el tejido es inadecuado, o adecuado pero con alteraciones inespecíficas o bien con ausencia de alteraciones patológicas. Por ejemplo en la serie de 7.257 biopsias procesadas en el Laboratorio de Nefropatología de la Universidad de Carolina del Norte en Chapel Hill, este valor fue del $11 \% 6$.

Cuando el patólogo es confrontado con los hallazgos de la biopsia renal, requiere de una clasificación morfológica (un catálogo de patrones morfológicos), para trabajar con un algoritmo y realizar el diagnóstico diferencial histológico entre más de sesenta 
glomerulopatías al mismo tiempo, o debe esperar a tener una historia clínica completa para saber la manifestación de enfermedad renal del paciente y las hipótesis clínicas planteadas. Esperar que la historia clínica esté completa para hacer un diagnóstico morfológico no ayuda al clínico (ni al paciente) y se pierde el objetivo por el que se hace la biopsia renal: «hacer un diagnóstico morfológico». Este diagnóstico morfológico complementará los hallazgos clínicos y conducirá a un diagnóstico final con significación clínica ${ }^{7,8}$.

Finalmente, sólo me resta agradecer a las personas que han sido fundamentales y decisivas en el rumbo que ha tomado mi vida profesional:

- al Dr. Italo Caorsi Chouquer, quien me dio las primeras lecciones de Patología Renal; al Dr. Sergio Mezzano Abedrapo, quien fue fundamental en el contacto con mi tutor en Nefropatología y me apoyó siempre en mi estadía en el extranjero;

al Dr. J. Charles Jennette de la Universidad de Carolina del Norte con sede en Chapel Hill, un gran maestro de la Nefropatología, reconocido a nivel mundial;

y a mi familia, que fue un apoyo moral incondicional en los momentos difíciles.

\section{REFERENCIAS}

1. Iversen $\mathrm{P}$, Brun $\mathrm{C}$ : Aspiration biopsy of the kidney. Am J Med 1951; 11: 324-30

2. Furness PN: Renal biopsy specimens. J Clin Pathol 2000; 53: 433-8

3. Nadal MA: Avances en glomerulopatías en los últimos 20 años. Rev Nefrol Dial Transp 2001; 53: $27-8$

4. Boulton-Jones M: Renal Biopsy. In: Johnson R, Feehally $J$ (eds). Comprehensive Clinical Nephrology. London, Mosby, 2000

5. Schwartz M: The Pathologic Diagnosis of Renal Disease. In: Jennette JC, Olson JL, Schwartz MM and Silva FG (eds). Heptinstall's Pathology of the Kidney.
Philadelphia, New York, Lippincott-Raven, 1998

6. Jennette JC, Falk RJ: Glomerular Clinicopathologic Syndromes. In: Greenberg A (ed). Primer on Kidney Diseases. San Diego, California, Academic Press, 1998. Section.

7. Hoffmann EO: Veterans Affairs Medical Center New Orleans, Louisiana State University Health Sciences Center Boulletin, 2001

8. Kern WF, Silva FG, Laszik ZG, Bane BL, Nadasdy T, Pitha JV (eds): Classification of Renal Diseases and Mechanisms of Renal Injury. In: Atlas of Renal Pathology. Philadelphia, Pennsylvania, W.B. Saunders Company, 1998 